\title{
Scaling Biodiversity Conservation Efforts: An Examination of the Relationship Between Global Biodiversity Targets and Local Plans
}

\author{
Jennifer Rae Pierce ${ }^{1,2 *}$, Sabrina Drill ${ }^{1,3 *}$, Michael D. Halder ${ }^{1}$, Mika Mei Jia Tan ${ }^{1,4}$, \\ Anushri Tiwari ${ }^{1}$ and Pablo A. López Guijosa ${ }^{1}$ \\ ${ }^{1}$ Urban Biodiversity Hub, Vancouver, BC, Canada, ${ }^{2}$ School of Community and Regional Planning, University of British \\ Columbia, Vancouver, BC, Canada, ${ }^{3}$ University of California Agriculture and Natural Resources, Los Angeles, CA, \\ United States, ${ }^{4}$ Association of Southeast Asian Nations (ASEAN) Youth Biodiversity Programme, ASEAN Biodiversity Centre, \\ Los Baños, Philippines
}

OPEN ACCESS

Edited by:

Daniel T. Blumstein University of California, Los Angeles,

United States

Reviewed by:

Pedro Segurado, University of Lisbon, Portugal

Daniel Steven Cooper, Natural History Museum of Los Angeles County, United States

*Correspondence:

Jennifer Rae Pierce piercestudio@gmail.com

Sabrina Drill sldrill@ucanr.edu

Specialty section: This article was submitted to

Global Biodiversity Threats, a section of the journal

Frontiers in Conservation Science

Received: 03 August 2021

Accepted: 25 October 2021

Published: 25 November 2021

Citation:

Pierce JR, Drill S, Halder MD,

Tan MMJ, Tiwari A and López Guijosa PA (2021) Scaling Biodiversity Conservation Efforts: An Examination of the Relationship Between Global Biodiversity Targets and Local Plans.

Front. Conserv. Sci. 2:752387. doi: 10.3389/fcosc.2021.752387
Cities have a critical role to play in meeting global-scale biodiversity targets. Urban socioecological systems connect human and ecological well-being. The outsized impact of cities reaches well-beyond their geographic borders through cultural, ecological, and economic interactions. Although cities account for just $2 \%$ of the earth's surface, they host over half of the human population and are responsible for $75 \%$ of consumption. The Parties to the Convention on Biological Diversity (CBD) and others have acknowledged the important role cities can play in achieving global targets. In response, at least 110 cities have produced plans focused on biodiversity, but we do not know the extent to which these city plans align with global targets or what role they play in achieving these targets. Here, we explore the relationship between global biodiversity conservation targets and local biodiversity plans to identify how elements at the two scales align or diverge. We compared the CBD Strategic Plan 2011-2020 (Aichi Targets) with 44 local biodiversity plans (often called LBSAPs) from cities around the world. We analyzed more than 2,800 actions from the local plans to measure the relationship with these global targets. Our results show how local approaches to biodiversity conservation can inform post-2020 global frameworks to improve coordination between global and local scale processes. We identify actions particular to the local scale that are critical to conserve global biodiversity and suggest a framework for improved coordination between actors at different scales that address their respective roles and spheres of influence.

Keywords: indicators, urban biodiversity conservation, urban planning, global biodiversity conservation targets, Aichi Biodiversity Targets

\section{INTRODUCTION}

While much attention to nature conservation and biodiversity loss has focused on remaining undeveloped "natural" areas and on national-level actions that target these places, the roles of urban areas and local governments should not be overlooked. Urban socio-ecological systems have critical and wide-ranging influence on societal norms, the health of people (Marselle et al., 2019), and biodiversity at a global scale (McDonald et al., 2018; Secretariat of the Convention on Biological Diversity, 2021). Cities are centers of innovation that can demonstrate the effectiveness of 
nature-based solutions (Kabisch et al., 2016) and promote sustainable lifestyles ${ }^{1}$. Urban and peri-urban land use patterns and the behavior of urbanites can play a critical and decisive role in meeting global biodiversity goals and targets and are critical to the implementation of international efforts to safeguard biodiversity (Puppim de Oliveira et al., 2011). There are 422 major cities located in biodiversity hotspots, and 383 of these are predicted to sprawl into ecologically significant areas (Weller et al., 2019). Although cities account for just $2 \%$ of the earth's surface area, they are home to over half of the human population and are responsible for $75 \%$ of consumption (Muller et al., 2010). It is clear that cities have a disproportionate impact on the earth's natural systems and the species that live within them (Puppim de Oliveira et al., 2011). Therefore, cities have the potential to shape society to one that protects nature, reduces harmful consumption patterns, and seeks out nature-based solutions.

Local governments have taken on this responsibility through the development and implementation of local biodiversity strategy and action plans, sustainability plans, habitat plans, and other related initiatives. The Urban Biodiversity Hub has gathered 123 biodiversity plans and/or reports produced by local governments (McDonald et al., 2018). These plans outline varied approaches that reconnect urban dwellers to nature, highlight the ecological footprint of cities, encourage conservation of nature in their respective regions, and increase resilience of urban socioecological systems to changing environmental conditions.

In 2008, the Parties to the Convention on Biological Diversity (CBD) recognized the significance of local governments in contributing to global goals through Decision IX/28, which called for national governments to support local governments in their efforts toward CBD targets (Secretariat of the Convention on Biological Diversity, 2008). In particular, the decision called for the adoption of local biodiversity strategy and action plans that would be consistent with their national-level counterparts. That same year, the Global Partnership on Local and Subnational Action for Biodiversity was launched at the International Union for Conservation of Nature (IUCN) World Conservation Congress, with the goal of coordinating local and subnational governments and their partners to implement the CBD. Since then, a Global Biodiversity Summit of Cities and Subnational Governments has taken place in parallel to each Conference of the Parties to the CBD. In 2010, at the Tenth Conference of the Parties to the CBD, the Aichi/Nagoya Declaration on Local Authorities and Biodiversity and the 2011-2020 CBD Plan of Action on Cities, Local Authorities and Biodiversity were adopted. Subsequently, a Decision related to subnational governments has emerged from each of the CBD Conferences of the Parties. However, only national-level governments have official standing to directly influence CBD decisions, and therefore CBD targets are more likely to reflect national-level priorities and approaches.

In 2010, the CBD created the Strategic Plan for Biodiversity 2011-2020, which included the 20 Aichi Biodiversity Targets with

\footnotetext{
${ }^{1}$ Yang, Y., and Taufen, A. (Eds.). (forthcoming, 2022). The Routledge Handbook of Sustainable Cities and Landscapes in the Pacific Rim. Routledge, Taylor Francis Group.
}

the vision of "living in harmony with nature." These targets sought to establish a framework for action for the decade, to be implemented by the Parties to the convention particularly through National Biodiversity Strategy and Action Plans. The 20 targets are organized under five strategic goals related to mainstreaming biodiversity, reducing pressures on biodiversity, safeguarding biodiversity's status, enhancing ecosystem services, and enhancing implementation of biodiversity initiatives. Nations then had the flexibility to set their own objectives within each of the 20 target areas. Unfortunately, the targets have largely not been met, and it has been suggested that this is linked to difficulty in translating them into specific actions (Green et al., 2019), among other limitations to their ability to be mainstreamed into other sectors and at other scales (MilnerGulland et al., 2021).

The year 2021 marks a turnover date, as the Aichi Biodiversity Targets are expiring and new targets are being negotiated. The successor to the Strategic Plan for Biodiversity 2011-2020 under the Convention on Biological Diversity (CBD), referred to as the Post-2020 Global Biodiversity Framework (GBF), is currently being negotiated to put nature on a path to recovery to reach the 2050 goals and continue the vision of "living in harmony with nature" (Secretariat of the Convention on Biological Diversity, 2021 , p. 4). Therefore, now is the time to synthesize lessons from practice from the past decade to inform a Post-2020 Global Biodiversity Framework that better integrates the role of cities in achieving global biodiversity goals and targets.

\section{Research Questions}

The goal of this research study is to examine the relationship between the Aichi Biodiversity Targets and stated actions in local biodiversity plans developed by cities for the urban context. We therefore address the following research questions:

1. Which Aichi Targets are commonly addressed in the actions of local biodiversity plans?

2. How are cities addressing the themes of the Aichi Biodiversity Targets through direct actions stated in their biodiversity plans?

3. What actions are cities including in local biodiversity plans that are not covered by the Aichi Biodiversity Targets?

\section{MATERIALS AND METHODS}

Our population of interest was defined as cities with a biodiversity plan. A biodiversity plan is "an official government strategy or a document primarily dedicated to biodiversity or ecosystem health that describes goals related to biodiversity and the actions needed to meet those goals" (McDonald et al., 2018, p. 53). Our initial search identified 113 such cities, so we elected to take a sample from cities with a population of more than 300,000 . Our sampling strategy aimed for geographical diversity, so we included the three most populous cities per country. To identify cities with plans, we started with the contents of the UBHub database and then supplemented these results with internet searches for the most up-to-date plans and for additional cities 
TABLE 1 | List of the 44 cities and their plans included in this study.

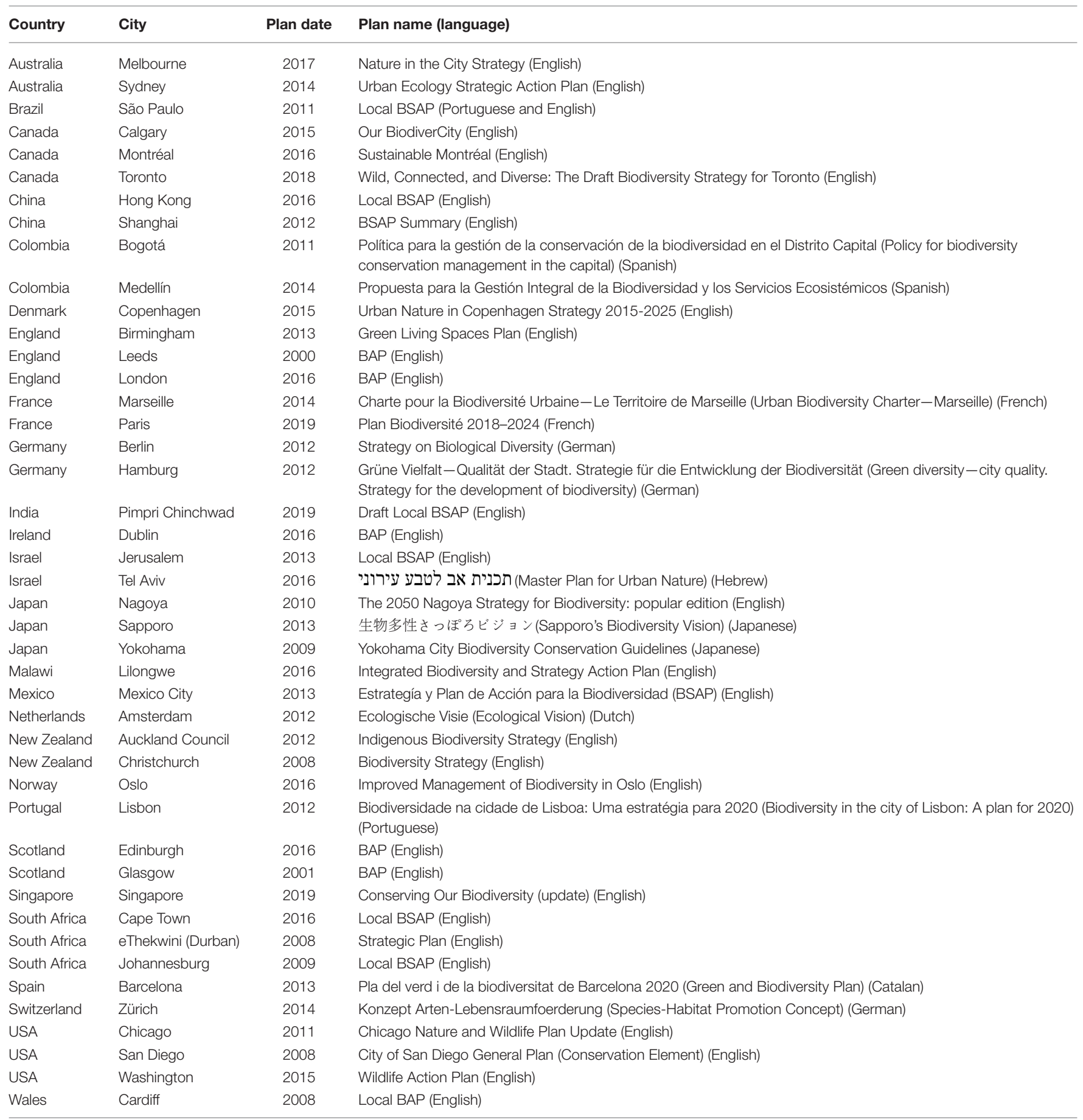

BSAP stands for Biodiversity Strategy and Action Plan. BAP stands for Biodiversity Action Plan.

that had published plans. We identified 44 city plans (in 26 countries) for analysis, listed in Table 1.

Some plans were not available in English. If we had a native speaker on the research team, we analyzed the plan in the original language. If we did not have a native speaker, we used Google Translate supplemented as necessary by professional translation services.
Our team then manually reviewed each plan, following standard protocols for qualitative content analysis (Krippendorff, 2003) and using a comparative approach (Berting, 1980; Lyles and Stevens, 2014). We extracted actions from each plan and coded them according to each of the 20 Aichi Target themes (designated as T1-T20), plus an additional category "not applicable" (n/a) for actions outside of these themes. Within each 
of these categories, we assigned the actions to inductively derived subcategories. To determine the category and subcategory, we reviewed the action text, as well as contextual information such as related targets, indicators, and objectives, to inform the coding selection. Across and sometimes even within the plans, we did not find a standard use of the term "action," and so we used the following definition from our previous work: "a specific action the city plans to take (or is taking), generally expressed with a verb" (Pierce et al., 2020). This approach allowed us to extract text that met our definition regardless of whether it was explicitly identified in the plan as an "action." When an action could be coded to more than one Aichi Target, particularly due to the overlapping nature of the Aichi Targets themselves, and because a single action may contribute to more than one Aichi Target simultaneously (Secretariat of the Convention on Biological Diversity, 2018), we chose the most relevant Aichi Target to maintain simplicity for this analysis.

To increase intercoder reliability and the consistency of the coding, we trained each member on the coding protocol, met weekly to discuss the coding, and reviewed the coding within each category. Any discrepancies were discussed among the team and resolved by consensus.

\section{RESULTS}

Every Aichi Target theme except one was found in at least some of the actions in each plan, though the prevalence and abundance of each theme varied widely. We defined prevalence as the percentage of plans within our sample in which the theme was present at least once. Abundance is the count of the actions coded to a theme within each plan.

The most prevalent themes, "Awareness increased" (AT1) and "Knowledge improved, shared, and applied" (AT19) were each addressed in $93 \%$ of plans. Other prevalent themes (found in at least $60 \%$ of plans) were "Ecosystems restored and resilience enhanced" (AT15) at 86\%, "Habitat loss halved or reduced" (AT5) at $84 \%$, "Protected areas increased and improved" (AT11) at $84 \%$, "Biodiversity values integrated" (AT2) at $80 \%$, "National

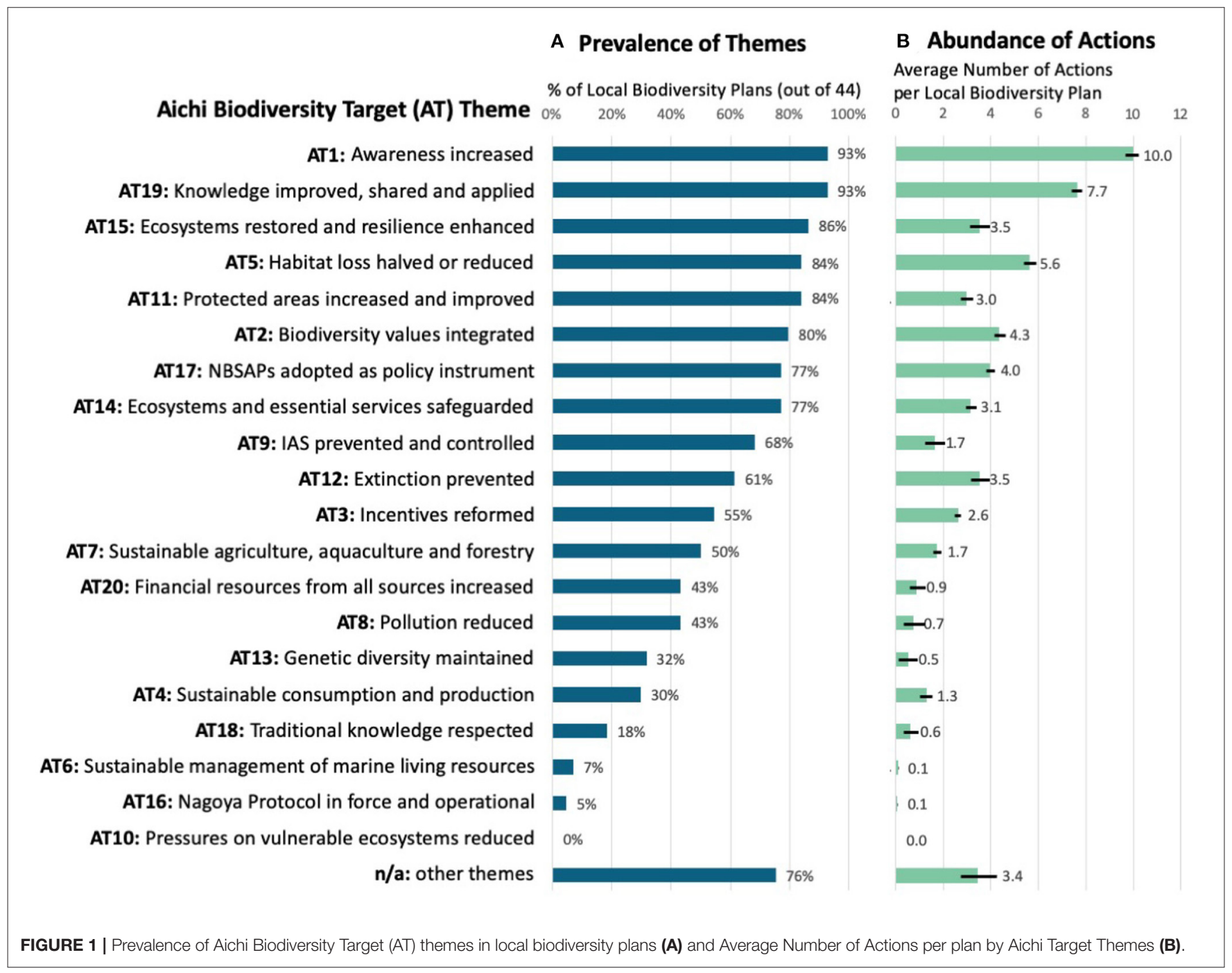


Biodiversity Strategy and Action Plans adopted as policy instrument" (AT17) at 77\%, "Ecosystems restored and resilience enhanced" (AT14) at 77\%, "Invasive alien species prevented and controlled" (AT9) at 68\%, and "Invasive Alien Species (IAS) prevented and controlled" (AT9) at 68\%. The theme of "Pressures on vulnerable ecosystems reduced" (AT10) was not found in any of the plans, though this theme overlaps with others that were found in the plans. The other two least prevalent themes, "Sustainable management of marine living resources" (AT6) and "Nagoya Protocol in force and operational" (AT16) were present in 7 and $5 \%$ of plans, respectively. The majority (76\%) of the plans also contained elements not covered by an Aichi Target (labeled "n/a"). The prevalence of each theme among the plans is illustrated in Figure 1A. The subcategories identified within each theme and their prevalence are available as Table 2.

In addition to the prevalence of themes within the plans, we also counted the number of plan elements (actions, indicators, and outputs) found in each plan. We then averaged this total over the 44 plans to determine the abundance of the theme, a measure of the average degree of detail per plan devoted to each theme. The results of this analysis are shown in Figure 1B. On average, there were 2.8 actions associated with any given Aichi Target theme (or "n/a") per plan. The two most abundant themes were the same as the two most prevalent themes, "Awareness increased" (AT1) and "Knowledge improved, shared and applied" (AT19), averaging 10.0 and 7.7 actions per plan, respectively. However, there were some themes with a lower average abundance than would be expected given their prevalence in the plans, in particular "Ecosystems restored and resilience enhanced" (AT15) at 3.5 average number of actions per plan, "Protected areas increased and improved" (AT11) at 3.0, and "Invasive alien species prevented and controlled" (AT9) at 1.7. Some other themes had much higher abundance than would be expected, in particular "Extinction prevented" (AT12) at 4.8 and "Genetic diversity maintained" (AT13) at 1.3.

Actions outside of the Aichi Target themes were prevalent, found in $76 \%$ of the plans and averaging 2.8 actions per plan (see Figure 1). The subcategories within this theme and their prevalence in the plans are outside cooperation (34\%), regulations/enforcements (32\%), vertical cooperation (20\%), human/wildlife conflicts and pests $(11 \%)$, increase staff (9\%), administration (7\%), procurement of resources (7\%), transportation $(7 \%)$, and procedural improvements (2\%) (see Figure 2).

\section{DISCUSSION}

The discussion is organized by Aichi Target (AT) themes, although sometimes overlapping themes are combined, indicated by their number in the subheading (i.e., AT1 indicates the theme for Aichi Target 1, "Awareness increased"). Themes commonly found in the plans but not covered by the Aichi Targets are discussed at the end of this section. Note that our discussion here is focused on the 12 most prevalent Aichi Target themes, sometimes grouped to address related themes together. Themes not discussed are "Sustainable consumption and production"
(AT4), "Sustainable management of marine living resources" (AT6), "Pollution reduced" (AT8), "Pressures on vulnerable ecosystems reduced" (AT10), "Genetic diversity maintained" (AT13), "Nagoya Protocol in force and operational" (AT16), "Traditional knowledge respected" (AT18), and "Financial resources from all sources increased" (AT20).

The quantity of actions per plan indicates the level of detail within each topic, which may imply the degree of familiarity and comfort of the cities in outlining each step of the process within this theme. Awareness and knowledge-sharing are the most common, and these are also activities that cities may be familiar with due to similar awareness-raising campaigns for other issues, like recycling. "Extinction prevented" (AT12) is also abundant, which may be a result of having ecologists or biologists involved in plan creation who have broken down these actions by species; in some cases, there may be a legal requirement to include particular detail at the species level (such as standard requirements in the United Kingdom or compliance with the Endangered Species Act in the United States). On the other hand, "Invasive alien species prevented or controlled" (AT9) is not as abundant, which reflects that plans more commonly state simplified general actions, rather than detailed step-by-step actions, to address this theme.

Both of the themes most commonly found in the plans (AT1 and AT19) are about information availability, promotion, and sharing, and this is important at the local level for biodiversity planning. These types of activities may be more fiscally feasible than on-the-ground implementation actions and also may be indicative of the early steps of a biodiversity campaign, namely, gathering data, and building public support. Research on this area based on surveys of participants also support the significance of these two themes at the local level, in particular their role in contributing to AT12 (Mair et al., 2021).

\section{Increasing Awareness (AT1)}

As hosts of educational, cultural, and media institutions as well as major population centers, cities are key to meeting biodiversity awareness-raising goals. While the physical outcomes of conservation-oriented land use are more visible, the transformation of urban economic, social, and cultural norms are needed to stop biodiversity loss (Dickman et al., 2015). Raising awareness of how a person's or institution's choices impact biodiversity, particularly for more indirect impacts, is therefore needed (Puppim de Oliveira et al., 2011). Cities are recognizing this need by including actions for awareness raising in nearly all of the plans included in this study. In fact, even though $87 \%$ of national governments contained targets related to awareness raising (Secretariat of the Convention on Biological Diversity, 2020), our research indicates that local governments are generally more likely (93\% of plans) than national governments to include this topic in their plans. Given the high prevalence of the increasing awareness topic in both national and local biodiversity plans, it suggests that awareness-raising is happening on a cross-scalar basis and that there is perhaps an alignment on actions to raise awareness about the importance of biodiversity. 
TABLE 2 | List of the subcategories identified within each of the Aichi Target themes (or, if there is not a theme, "n/a") and their prevalence as a percentage of the plans.

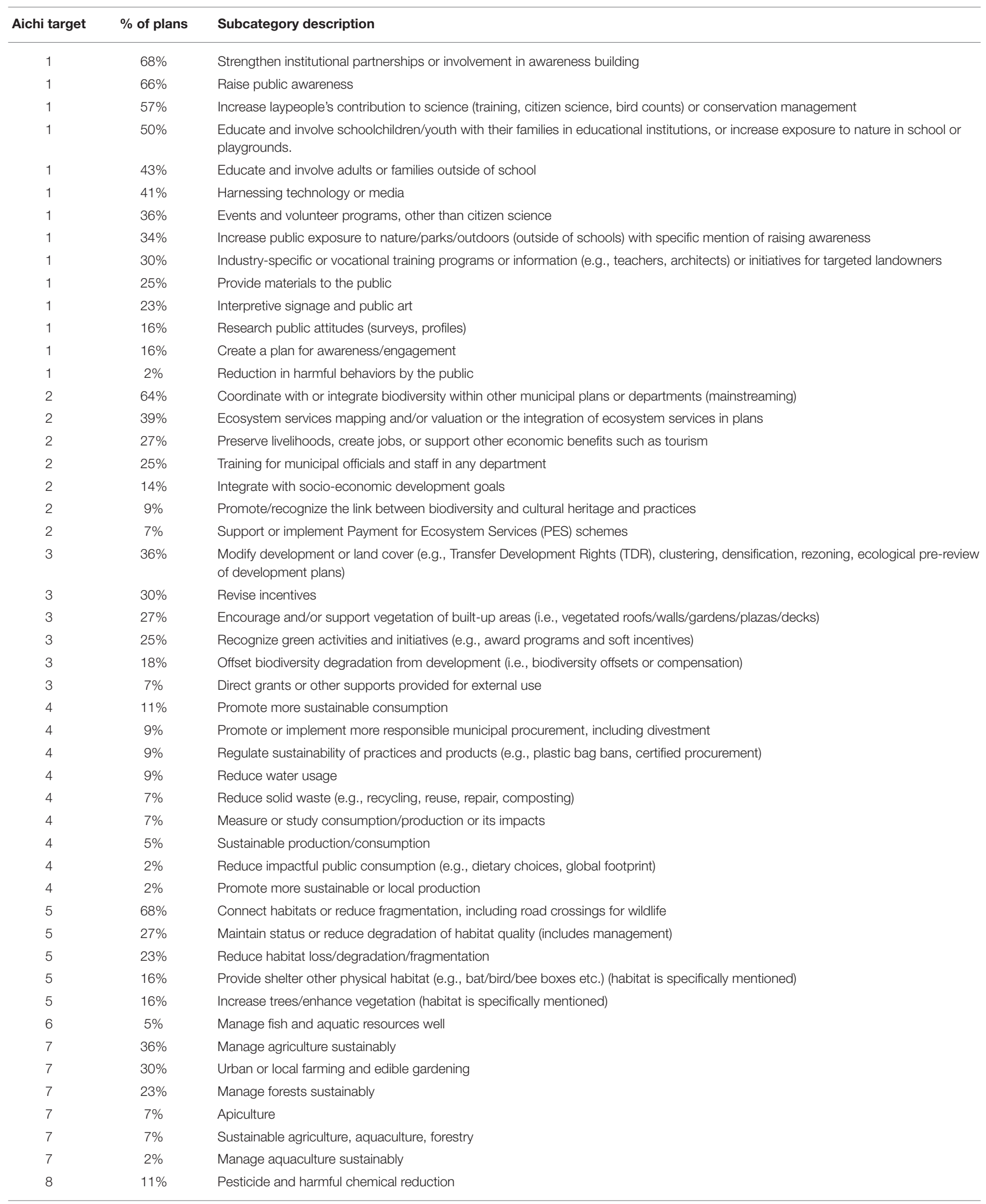


TABLE 2 | Continued

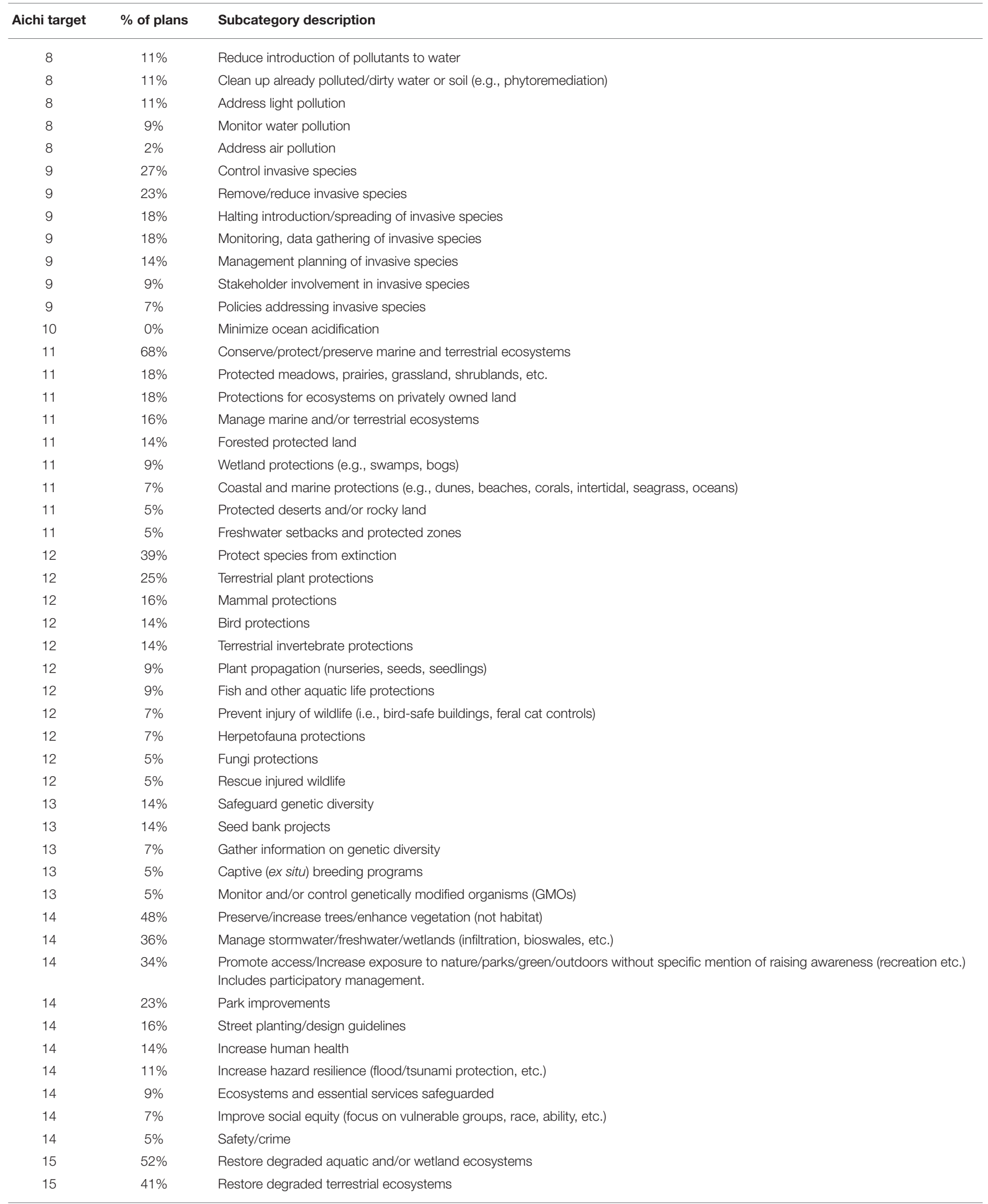


TABLE 2 | Continued

\begin{tabular}{|c|c|c|}
\hline Aichi target & $\%$ of plans & Subcategory description \\
\hline 15 & $34 \%$ & Mitigate and adapt to climate change (includes restoration of habitat) \\
\hline 15 & $14 \%$ & Adapt to the impacts of climate change \\
\hline 15 & $7 \%$ & Offset greenhouse gas (GHG) emissions (boost carbon stocks of soil, trees, etc.) \\
\hline 15 & $5 \%$ & Reduce GHG emissions (i.e., reduce energy use, fossil fuel use) \\
\hline 16 & $5 \%$ & Enforce Nagoya Protocol and related international trade \\
\hline 17 & $45 \%$ & Create a related plan, such as a conservation plan, habitat plan, species plan, green spaces plan, or management plan \\
\hline 17 & $41 \%$ & Monitor or report on biodiversity plan(s) \\
\hline 17 & $34 \%$ & Encourage participatory planning \\
\hline 17 & $32 \%$ & Implement an LBSAP/management plan \\
\hline 17 & $16 \%$ & Create, approve, or update an LBSAP \\
\hline 18 & $16 \%$ & Protect indigenous traditional use and ecological knowledge \\
\hline 19 & $59 \%$ & Gather baseline or historical data \\
\hline 19 & $50 \%$ & Encourage research including funding and training programs on biodiversity \\
\hline 19 & $39 \%$ & Ongoing monitoring after baseline data has been collected or a project is started \\
\hline 19 & $36 \%$ & Apply ecological knowledge in conservation planning and action \\
\hline 19 & $32 \%$ & Map biodiversity information, such as through GIS \\
\hline 19 & $30 \%$ & Report the status of local biodiversity/information sharing such as via online platforms or shared databases \\
\hline 19 & $25 \%$ & Comply/coordinate with regional, national, or international initiatives \\
\hline 19 & $23 \%$ & Provide open datasets or online platforms \\
\hline 19 & $14 \%$ & Provide a centralized database of biodiversity information \\
\hline 19 & $11 \%$ & $\begin{array}{l}\text { Participate in existing international commitments, programs, or standards that include collecting and/or sharing biodiversity } \\
\text { information }\end{array}$ \\
\hline 19 & $11 \%$ & Provide updated progress reports on status of targets/implementation \\
\hline 19 & $9 \%$ & Verify the status of current standards to see if it is up to date \\
\hline 19 & $9 \%$ & Gather data on the management status of biodiversity \\
\hline 20 & $25 \%$ & Raise/apply external funding \\
\hline 20 & $18 \%$ & Local funding commitments (may be mixed with external funds) \\
\hline 20 & $7 \%$ & Commit financially \\
\hline $\mathrm{n} / \mathrm{a}$ & $34 \%$ & Actions that strengthen cooperation with entities that are not the city itself, including NGOs \\
\hline $\mathrm{n} / \mathrm{a}$ & $32 \%$ & Develop, enforce, or amend local regulations and standards for biodiversity \\
\hline $\mathrm{n} / \mathrm{a}$ & $20 \%$ & Actions that strengthen cooperation across different government scales only, including advocacy \\
\hline $\mathrm{n} / \mathrm{a}$ & $16 \%$ & Wildlife conflicts and pests \\
\hline $\mathrm{n} / \mathrm{a}$ & $11 \%$ & Participate in existing international commitments, programs, or standards \\
\hline $\mathrm{n} / \mathrm{a}$ & $11 \%$ & Reduce trafficking/poaching and crime \\
\hline $\mathrm{n} / \mathrm{a}$ & $9 \%$ & Increase staff capacity \\
\hline $\mathrm{n} / \mathrm{a}$ & $7 \%$ & Internal administrative activities \\
\hline $\mathrm{n} / \mathrm{a}$ & $7 \%$ & Increase access to materials and physical resources \\
\hline $\mathrm{n} / \mathrm{a}$ & $7 \%$ & Transportation-focused actions \\
\hline $\mathrm{n} / \mathrm{a}$ & $2 \%$ & Procedural improvements, primarily related to environmental assessments \\
\hline
\end{tabular}

Within actions under this theme, the two most common subcategories, institutional partnerships in the community (68\% of plans) and general awareness-raising statements (66\% of plans), tend to be rather generic. The former demonstrates a desire to cooperate with external groups, suggesting that cities recognize the potential opportunities that these groups bring or possibly that they are feeling too under-resourced to accomplish their awareness-raising goals by themselves. Within this subcategory, Calgary is striving "to remove knowledge and institutional barriers to protect biodiversity" and San Diego is planning to "facilitate public-private partnerships that improve private, federal, state, and local coordination through removal of jurisdictional barriers that limit effective wetland management," while cities like Copenhagen, Dublin, Edinburgh, London, Nagoya, Paris, Sydney, Tel Aviv, and Yokohama are working to establish linkages with students, practitioners, decision makers, business entities, and society at large to support implementation of urban-biodiversity-related projects and policies in their respective cities.

Under general awareness-raising statements, the actions as listed do not include enough detail to be subcategorized 


\section{Actions in Local Biodiversity Plans Outside of the Aichi Target Themes}

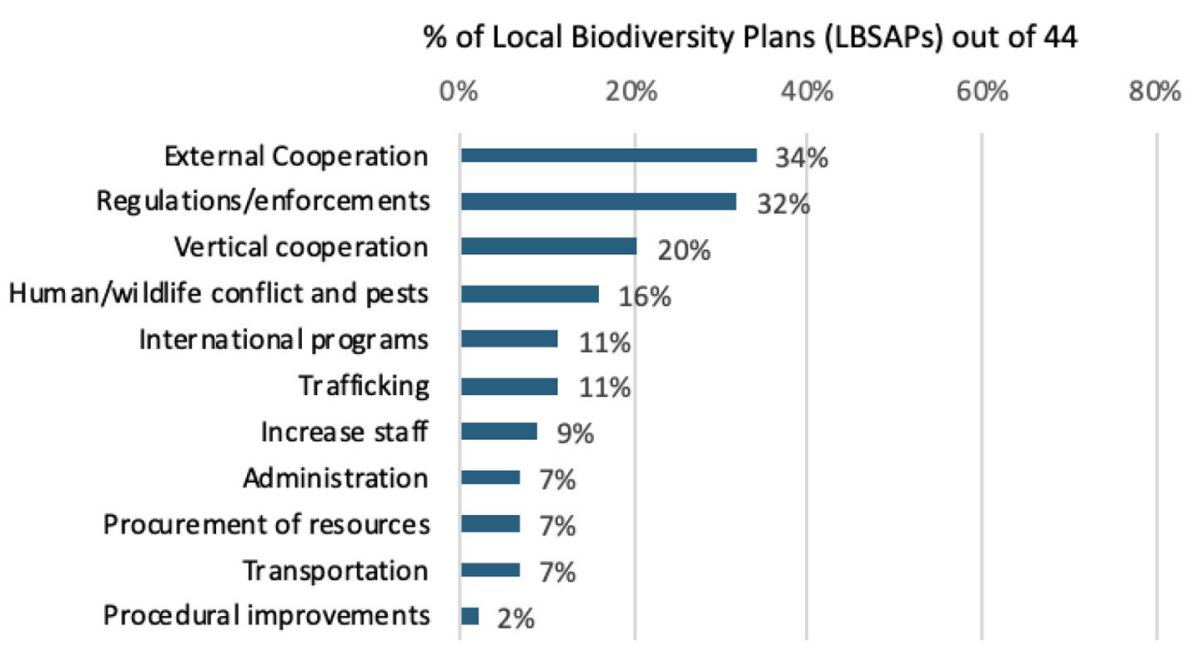

FIGURE 2 | Prevalence of other topics outside of the Aichi Biodiversity Target (AT) themes in local biodiversity plans.

further. Paris, for example, has indicated their effort to examine the number of "participants sensitized to biodiversity" in their public awareness events and campaigns. Cape Town stated they would "communicate the message of biodiversity conservation, especially the benefits that biodiversity provides to the community by means of appropriate media." This lack of detail may imply that some cities are not yet sure how they would particularly fulfill objectives related to awareness raising.

The most common awareness-raising approach in the plans is through citizen science programs (57\% of plans). Actions in the plans included promoting volunteer initiatives, conducting surveys, and encouraging participatory science programmes that enhance the community's engagement with the local biodiversity. Sydney's plan had a section on "community engagement" in which the city intends to "support and encourage bush restoration groups," along with increasing the "community's participation in bird surveys and planting activities." These results reflect the increasing attention citizen science has gained as a useful and meaningful tool for advancing ecological science (Silvertown, 2009; Wei et al., 2016), as it allows the citizens to contribute and be a part of the larger agenda of safeguarding nature.

The next most common actions cities listed fell under education-related activities, including school programs (50\% of plans) and education of the general public (43\%). The focus for school programs was to include biodiversity and its values in school curricula and education programmes (Berlin, Cape Town, Lisbon, Yokohama, and Sapporo); to practice exercises and provide fun activities, and kits in the gardens and parks (Paris, Glasgow, and Tel Aviv); and to encourage research projects on wildlife (Edinburgh). The decision of whether to mention school programming in plans may have been influenced by the scale at which school curricula are determined, since these are sometimes the domain of a different scale of government. However, education of the general public would not be as limited by government domains. Some of these actions were quite specific, such as these actions from London's plan: "Incorporate biodiversity enhancements into community food growing schemes" and "Promote good practice guidance to food growing groups and include in City in Bloom judging criteria." Others left their statements open for interpretation, such as this action from Medellín: "Citizen education and wildlife conservation." These types of actions directed toward the public rarely included details on how they would be measured, whereas public school curricula are sometimes measured based on the number of schools or students participating. Cities may therefore benefit from guiding principles and best practices for local actions for education-related awareness raising.

Less common actions under this theme (in order from most to least prevalent subcategory) are the use of media (including online communications), holding events or calling for volunteers, directly exposing people to nature, targeted programming for particular groups, providing information for the public, installing artwork or signage, conducting surveys, creating an awareness plan, and supporting behavioral changes directly. This wide array of actions under the umbrella of awareness raising indicates how cities are creatively addressing this problem. Four of these subcategories are primarily passive communications, and only two (events and volunteer involvement in 36\% of plans and increasing exposure to nature in 34\%) involve hands-on interaction with nature. Research has suggested that hands-on contributions and exposure are an important tool for increasing awareness raising for biodiversity (Kendall et al., 2006; Stern et al., 2017) but our results suggest that cities may need additional support or incentives to increase the prevalence of actions that harness experiential opportunities for awareness raising. The 
hands-on activities occur at local scales where they allow for the meaningful engagement of local citizens. As such, strategic support and incentives from national or regional levels of government directed at local communities within cities might help with awareness-raising for biodiversity.

\section{Integrating Biodiversity Values (AT2)}

Mainstreaming biodiversity or, in other words, integrating biodiversity objectives and approaches across all sectors, is another key part of meeting global biodiversity goals (Cities Alliance, 2007) and is addressed in Aichi Target 2. Local actions in this theme integrate and reflect the contribution of biodiversity and the ecosystem services it provides into relevant planning processes and strategies, policies, programmes, and reporting systems, thereby mainstreaming biodiversity into the decisionmaking framework of the municipality. Accordingly, the majority $(80 \%)$ of cities included this theme in their biodiversity plans. This rate is comparable to that in national plans, with $84 \%$ of National Biodiversity Strategy and Action Plans containing targets related to Aichi Biodiversity Target 2 (Secretariat of the Convention on Biological Diversity, 2020). More specifically, $64 \%$ of local plans discussed coordination with or integration of biodiversity into other municipal plans, decision-making tools, or departments. For example, Cape Town described how spatial biodiversity data could be integrated into decision making and Zürich mentioned integration into consultation related to land use and urban planning, among other actions. Other cities were less detailed and mentioned this theme in fewer, broader actions, such as "mainstreaming biodiversity into all city planning and other relevant municipal documents" (Jerusalem). At the other end of the spectrum, Auckland specified several indicators for measuring their mainstreaming activities, such as "number of inter-council projects" and "increased reference and commitment to biodiversity in formal planning documents," which could be useful for review and possibly adoption by other municipalities. Actions in this theme signal that cities understand that achieving biodiversity outcomes will take a broader collaboration inclusive of non-typical departments and mandates. It is noteworthy that $25 \%$ of plans mentioned training of municipal staff (including those outside biodiversity-related departments) on the importance of biodiversity, which is an important first step to mainstreaming nature in the work of other departments. It was not apparent whether or not this level of detail was included in national biodiversity plans (Secretariat of the Convention on Biological Diversity, 2020), but the detail at the local level illustrates that local plans can include important intermediary steps that contribute to biodiversity outcomes. Moreover, this suggests that integrating biodiversity values may be occurring at multiple governance scales which is helpful for taking comprehensive and complementary actions to address the issue of biodiversity loss.

Seeking to valuate and account for ecosystem services is part of $39 \%$ of plans, reflecting the need to quantify biodiversity's value in order to mainstream and integrate it into other plans. Most local plans, however, made general statements such as "Commission a study on the ecosystem services provided by major habitat types" (Hong Kong), "Determine the values and uses of biodiversity to local communities and households" (Johannesburg), or "promote and participate in the developing of methodology for valuing biodiversity in the city" (São Paulo), indicating that municipalities may be at the initial stages of ecosystem services valuation. Cities also lack standards for valuation. At the national scale, 91 countries have used the System of Environmental-Economic Accounting (SEEA) framework that provides internationally agreed standard concepts, definitions, classifications, accounting rules and tables for producing internationally comparable statistics and accounts (Smith, 2007). However, the SEEA framework is unsuitable for the urban level (Barton et al., 2017) and different methodologies are employed by different cities to value ecosystem services (Croci et al., 2021). None of the plans identified specific frameworks or methods for valuing ecosystem services. It may therefore benefit municipalities to have a standardized method for valuing ecosystem services at the urban level.

Within this theme, only $27 \%$ of cities stated actions to preserve livelihoods, create jobs, or support other economic benefits (such as tourism), reflecting that mainstreaming may not be seen as a two-way street. An even smaller percentage (9\%, i.e., Paris, São Paulo, and Shanghai) mentioned establishing schemes or mechanisms for payment for ecosystem services.

\section{Incentives Reformed (AT3)}

More than half (55\%) of local plans addressed the theme of "Incentives reformed" (AT3). This theme is about encouraging members of the public or non-governmental institutions to make choices that better support biodiversity conservation. At the local scale, actions planned under this theme were relatively evenly distributed across the subcategories. Common actions included generic statements about incentives (30\%), incentives for revising land development patterns or land use cover (36\%), incentives for vegetation such as green roofs and walls (25\%) and biodiversity offsets (18\%). Less common were direct grants and other supports, at only $7 \%$ of plans. Some incentives were closely related to regulatory action, such as Berlin's action to "Apply standards in civil engineering and procurement that preserve and respect biodiversity" while others were more explicit about providing incentives such as eThekwini's action to "Influence the valuation policy to incentivise conservation landuse on private land." As is perhaps to be expected, the positive incentive measures at the national scale are understandably broader and wide ranging such as supporting farmers through agri-environment schemes or reducing taxes and payment for ecosystem services (Secretariat of the Convention on Biological Diversity, 2020); whereas, at the local scale, the incentives appear to be targeted at influencing land use development patterns.

\section{Habitat Loss, Protected Areas, and Endangered Species (AT5, AT11, and AT12)}

It is widely recognized that habitat loss is the main driver of biodiversity loss at a variety of scales, including the local scale (Chase et al., 2020). Aichi targets 5, 11, and 12 all directly address the loss of biodiversity and habitat. Target 5 aims to reduce habitat loss by reducing the rate of loss to at least half of the current rate or close to zero. Target 11 sets specific numerical 
goals for protected areas (17\% of terrestrial and inland aquatic habitats and $10 \%$ of coastal and marine areas) for the habitat areas in protection. Target 12 focuses specifically on threatened species and aims to prevent their extinction and if possible, to improve their conservation status. Most cities recognize these direct impacts in their biodiversity plans. More specifically, the majority (84\%) of local biodiversity plans addressed habitat loss (AT5), protected areas (also 84\%) (AT11), and the need to conserve threatened species found within cities (61\%) (AT12).

Among the actions related to each of these targets, we identified several important subcategories. Under habitat loss (AT5), the most common approach was to focus on habitat connectivity, with $68 \%$ of plans taking this approach. Amsterdam and Cardiff in particular focus on this issue with large numbers of intended actions related to reconnecting habitat patches. In Amsterdam, these intended actions include the construction of faunal exit sites along various canals, as well as connectors across roads. Other cities state more general actions such as "Enhance habitat connectivity and establish ecological corridors across the boundary" (Hong Kong), "Integrate ecological corridors into urban planning documents" (Marseille) or the multiple objective "Promote green infrastructure in the built environment to help nature to adapt to climate change by strengthening habitat networks, reducing habitat fragmentation and providing opportunities for species to migrate" (Edinburgh). Infrastructure modification or new construction to support wildlife movement can be an effective form of mitigation of the habitat impacts of economic development (Sijtsma et al., 2020). It makes sense that habitat connectivity would be a central theme in urban areas, where development has been a primary cause of habitat fragmentation (Liu et al., 2016), and where alterations to built infrastructure (overpasses, culvert alterations, hedgerows, etc.) can possibly reconnect habitat for particular species. Some of this infrastructure exists on public property, where cities have the authority to take action. To increase opportunities for implementation success, local agencies can create clear policies and activate methods such as zoning incentives to cultivate public-private partnerships important for success (Keeley et al., 2018). These are interventions and land use decisions that function at the local, rather than global or national, scale.

General habitat protection, maintenance, and the prevention of degradation was included in $27 \%$ of plans, with some very specific examples such as "Relax grass cutting in appropriate sites. Compliment biodiversity-friendly sustainable planting to create and maintain habitat features (e.g., berry hedges, "nectar borders") which will benefit bees" (Edinburgh) and others that were much more general such as "Good maintenance of forest land that is the habitat of living creatures" (Nagoya). Improving the urban habitat with artificial enhancements was included in $16 \%$ of plans, including the installation of bird and bat boxes, water sources, and, in Paris, "insect lodges." The use of artificial enhancements can mitigate the loss of structural habitat, such as tree cavities, in urban areas where hazards are commonly removed for public safety (Harper et al., 2005). Planting trees and other vegetation specifically to improve habitat was also included in $16 \%$ of plans. These kinds of hands-on activities can address habitat improvement at the local scale, and are within the purview of municipal governments. If residents are directly involved in activities such as wildlife gardening or other forms of stewardship, these activities have the added benefit of contributing to personal well-being (Mumaw et al., 2017) and exposure to nature (AT14) and increasing awareness of nature (AT1), as well as promoting a stewardship identity among residents (Merenlender et al., 2016).

The use of protected areas has been one of the cornerstones of biodiversity conservation for decades (Rodrigues et al., 2004). However, protected areas are often seen as a response to urbanization (McDonald et al., 2018) rather than a mechanism to protect biodiversity within cities, though there are exceptions that conclude that urban protected areas can be important for the protection of biodiversity (Trzyna, 2014). In our data set, activities related to protected areas (AT11) ranged from the very vague [e.g., "preserve nature areas" (Marseille) and "Preservation of particularly endangered habitats and introduction of new valuable habitats in the city" (Berlin)] to the very specific [e.g., "Act to conserve the coastal sand dunes at Cramond" (Edinburgh)], which reflects a wide and non-specific range of protection approaches available to cities. In some cases, cities echo the numerical goals described in AT11 itself-“Turn 10\% of the land into conservation areas (Hamburg)" - or describe the formation of new parks "Develop a nature park at Long Valley for supporting conservation and agriculture in this ecologically important area" (Hong Kong) or "Designate all qualifying sites as SINC (Sites of Interest for Nature Conservation)" (Cardiff). More commonly, while preservation is a goal, no specific mechanism for protection is described. In cities, there is often more funding available to purchase land for protection than there is to maintain protected areas, even though studies have shown that a lack of attention to the need to support sufficient and equitable management of protected areas leads to a loss of effectiveness (Maxwell et al., 2020). We found that while $84 \%$ of plans mention protected areas either in general or in reference to specific habitat types, only $16 \%$ explicitly address management. A small proportion of plans addressing the management of protected areas suggests that, at the local scale, management may not always be a priority or even feasible due to cities being primarily human-dominated landscapes with competing demands for space and resources. At larger geographic scales, protected areas management may be easier to achieve because they are in less developed areas. While the use of protected areas for urban conservation may vary in its success, they have additional benefits, such as increasing human well-being and resilience to changing conditions (see AT14) and deriving support for the protection of nature among residents of densely populated areas (see AT1) (McNeely, 2001).

Aichi Target 12 specifically addresses threatened species. Cities can function as hotspots for threatened species. For example, one study found that Australian cities harbor a disproportionate amount of threatened species compared to more "natural" areas (Ives et al., 2016). This may be because cities "can provide more stable resources throughout the year" (Ives et al., 2016, p. 124), although they also found that cities contain threats to biodiversity and that relatively young cities may have an "extinction debt" (Hahs et al., 2009). Of course, it may also be 
that the same factors that drive the establishment and growth of cities (such as access to a freshwater source) may also drive increased biodiversity, and that biodiversity plus development leads to high numbers of threatened species in cities. We found that cities outlined actions to benefit species of concern within their boundaries in ways that may only differ in geography from similar actions that are taken in less developed areas. Examples include "threatened exotic plant species are cultivated in Council parks and gardens" (Christchurch), or "increase the number of breeding sites available to terns in the Firth of Forth" (Edinburgh).

\section{Invasive Alien Species Removed and Controlled (AT9)}

Invasive species have been identified as one of approximately seven direct drivers of biodiversity loss worldwide (Díaz et al., 2015). The majority (68\%) of plans contained one or more actions addressing the theme of "Invasive alien species (IAS) prevented and controlled" (AT9). Subcategories within this theme were relatively predictable, including controlling (27\%), removing/reducing (23\%), halting the spreading or introduction (18\%), monitoring (18\%), or managing (14\%) invasive alien species. Less common actions were involving stakeholders (9\%) or introducing policies (7\%) to control invasive alien species. Overall, cities took common approaches according to their local context and none questioned traditional approaches to invasive species management that can have implications for establishing more recent human migrants (Colautti and MacIsaac, 2004; Trigger et al., 2008), conflicts of interest among stakeholders (Novoa et al., 2018), such as findings about potential positive or regenerative potential of invasive species in novel ecosystems and conditions found in cities (Kowarik, 2011), as well as questionable ethics of particular practices and their efficacy (Doherty and Ritchie, 2017). Cities need approaches to address invasive species that are particular to their context as novel ecosystems with consideration for the human cultural context and evidence-based recommendations. Cities also are not yet addressing controversies over the definition of "natural" or how baseline conditions or other targets related to this concept are set, though recent papers have raised these concerns (Robbins and Moore, 2013).

\section{Ecosystem Services and Productive Landscapes (AT14, AT7)}

Another prominent theme we found in the plans is that of ecosystem services. Appearing within $77 \%$ of the plans, ecosystem services is a theme that is most directly, but not exclusively, captured by Aichi Target 14 (AT14), "Ecosystems and essential services safeguarded," which seeks to achieve the global goal of enhancing the services provided by biodiversity for all (Secretariat of the Convention on Biological Diversity, 2012). While generally defined as the benefits humans derive from ecosystems (Millennium Ecosystem Assessment (Program), 2005). Langemeyer and Gómez-Baggethun (2018) offer a more precise definition of ecosystem services for the urban context as those services supplied by the natural and engineered green and blue spaces in cities. These ecosystem services are classified as regulating (air quality, temperature, and flood control), provisioning (food, fiber, and water), habitat/sustaining (core ecological processes and functions such as nutrient cycling and the hydrologic cycle), and cultural (mental well-being, social cohesion, and spiritual enrichment) (Langemeyer and GómezBaggethun, 2018). Our research shows that each of the four types of ecosystem services are present in one form or another within the plans, even if the planned actions are not explicitly characterized as ecosystem services.

Within AT14, planned commitments to preserve, increase, or enhance vegetation were evident in $48 \%$ of the plans. The predominance of the vegetation subcategory is perhaps a recognition of the key role played by vegetation in urban areas in the delivery of a multitude of ecosystem services, which include carbon sequestration, runoff mitigation, noise reduction, and food supply, among others, along with its value for recreational and cultural purposes (Gomez-Baggethun et al., 2013; Berland et al., 2017; Langemeyer and Gómez-Baggethun, 2018). Action statements such as "To create seasonal gardens in urban squares" (Barcelona), "Identify sites or projects for temporary greening on vacant and derelict land" (Edinburgh), "Afforestation along river banks" (Lilongwe), "Double the number of green roofs on municipal buildings" (Montreal), "To increase the biodiverse vegetation in the city" (São Paulo), or "Creating vertical gardens/green walls on Metro Lines Pillars in selected locations" (Pimpri Chinchwad) suggest that the sampled cities appear to support the growth of vegetation within a diversity of urban green spaces (i.e., remnant habitats, yards, parks, vacant lots, engineered green infrastructure such as green roofs/walls, etc.). However, only a few of these planned actions describe how these urban green spaces are to be managed. This matters because the management of these urban green spaces at the city, neighborhood, and local scales will affect their capacity to support biodiversity and to deliver critical ecosystem services (Aronson et al., 2018). Furthermore, the ability of cities to support both plant and animal biodiversity and to provide ecosystem services is dependent upon the amount and quality of the urban green space (Cilliers et al., 2013), as well as how they are designed and managed (Aronson et al., 2018). It is not always clear if the planned city actions within the plans give any or much due consideration to the questions of scale, quality, or design of the various urban green spaces for vegetation to thrive. At the local scale, these other considerations may not always inform decisions to preserve or enhance vegetation cover in the city as there may be other factors or concerns such as funding, recreational uses of the green space, etc. that are particular to cities.

Both regulating and cultural ecosystem services in the form of planned actions on stormwater management and access to greenery, respectively, were among the prominent types of ecosystem services that the sampled cities included in their plans. Planned actions related to stormwater management were evident in $36 \%$ of the plans. The policy commitments for stormwater management mostly focused on increasing the permeability of surfaces to allow stormwater to infiltrate (Barcelona, Yokohama, Lisbon, and Washington, DC) with only a few also explicitly tying such commitments to biodiversity (Glasgow, Johannesburg, 
and San Diego), perhaps suggesting potential for integrating biodiversity with stormwater initiatives and also suggesting that simplified approaches to stormwater, such as using more permeable materials, is easier to implement than more complex projects that incorporate habitat areas or other vegetation for the sampled cities.

Planned actions related to access to greenery were included in $34 \%$ of plans through such actions as "Promote proximal natural environments for children living in densified areas" (Berlin), "Increase habitat diversity in private, public and institutional open space to aid appropriate access to and use of nature for citizens" (Calgary), "Promote reserves as places of safety and tranquility" (Cape Town), "Network of urban and rural public spaces as scenarios for the appropriation of the territory with emphasis on biodiversity" (Medellín), and "Create opportunities to get close to the city rivers by improving the waterfront environment such as green areas and walking paths" (Sapporo), among others. The relative prevalence of planned actions associated with stormwater management and access to greenery as types of regulating and cultural ecosystem services, respectively, is a reflection of cities as primarily humandominated landscapes. And, as such, intended actions designed to make the physical state of cities more hospitable for human settlement are likely to be included in the plans. Indeed, as Langemeyer and Gómez-Baggethun (2018) note, both regulating and cultural ecosystem services feature prominently within urban planning and within strategies for urban green infrastructure, respectively. The local-scale policy commitments for regulating ecosystem services, in particular, may serve as a helpful response to the Global Biodiversity Outlook 5 report, which finds globalscale regulating ecosystem services declining, a trend that can hamper the capacity of ecosystems to support people (Secretariat of the Convention on Biological Diversity, 2020).

The provisioning of ecosystem services is evident within the planned actions of the plans coded under Aichi Target 7 (AT7), "Sustainable agriculture, aquaculture and forestry." AT7 seeks to achieve the conservation of biodiversity through the sustainable management of agricultural, aquacultural, and forestry operations (Secretariat of the Convention on Biological Diversity, 2013). At the local scale, this global target translates into planned actions coded under the subcategories of manage agriculture sustainably, farming and edible gardening, and manage forests sustainably. These subcategories underscore the importance of the productive potential of urban or near urban lands for food and fiber. With respect to urban agricultural practices, planned actions such as "To promote organic agriculture in urban and peri-urban areas" (Barcelona), "Maximize the potential of hosting biodiversity in urban agriculture sites" (Paris), "To encourage practices of agroecology and permaculture" (São Paulo), "Creating farmland with consideration for living things" (Nagoya), and "Integrate agriculture and sustainability principles that promote clean air and water, and healthy soils, habitats, and ecosystems" (San Diego) seem to suggest that cities are committing to incorporating ecological approaches into urban agriculture. This approach appears to align with the intent of AT7, as urban agricultural sites can, when designed and managed intentionally for biodiversity, sustain a greater abundance of species of plants, birds, and arthropods compared to that of the surrounding urban matrix (Goddard et al., 2010 in Lin and Egerer, 2018). This is especially true for species of bees, flies, spiders, and beetles that provide key ecological functions such as pollination and pest predation that help to produce plants and crops in urban agricultural systems (Lin et al., 2015 in Lin and Egerer, 2018). These local-scale policy commitments for managing agriculture sustainably serves as a response to the decline of agricultural biodiversity, particularly with the reported decline in the abundance and diversity of pollinating species, which can contribute to lower crop yields (Secretariat of the Convention on Biological Diversity, 2020).

The provisioning of ecosystem services was also evident within the farming and edible gardening subcategory of AT7. Planned actions such as "Increase the number of people growing their own food and/or the number of food growing areas, targeting areas of deprivation (Edinburgh), "Citizens participate in food production through the promotion of citizen farms and rice paddies" (Nagoya), "Develop vegetable streets and experiment with an edible street" (Paris), "Facilitate community food growing and orchards" (Birmingham), "Encourage community gardens to incorporate habitat features" (Sydney), and other similar types of policies point not only to the different types of urban agricultural systems being supported, but they also lend credence to urban agriculture gaining support for its potential for increasing food security and nutrition (Lin and Egerer, 2018). While farming and edible gardening is increasingly supported within and around cities to address food security concerns and to improve the health of their residents (Lin and Egerer, 2018), the role played by urban gardening does differ among cities. Urban gardening in richer cities primarily fulfill recreational and cultural purposes since richer cities are likely to be well-integrated into global markets and food supply chains (Langemeyer and Gómez-Baggethun, 2018). Urban gardens in poorer cities, on the other hand, are essential food supply areas for their local populations (Langemeyer and Gómez-Baggethun, 2018). As such, the sites of urban agriculture, which can and do play a key role for biodiversity and in local food production (Smit et al., 1996 in Lin and Egerer, 2018), potentially serve the needs of socially and economically disadvantaged populations by safeguarding for them critical provisioning ecosystem services, which is a key consideration of AT14 (Secretariat of the Convention on Biological Diversity, 2013). At the local scale, community-oriented urban agriculture allows for a more meaningful and direct engagement with the food that is cultivated and the biodiversity that supports it. Such direct and meaningful engagement may not be possible at other scales at which food crops are cultivated.

\section{Ecosystems Restored and Resilience Enhanced (AT15)}

Climate change is seen as a key determinant of biodiversity loss. At the same time, the loss of biodiversity intensifies the effects of climate change (Kapos et al., 2008; Reed, 2012). This impact is significant in urban areas where large populations, including vulnerable communities, are vulnerable to extreme events (Solecki et al., 2011). The biodiversity in cities is also threatened by these sudden events (Wilby and Perry, 2006). Cities are 
heavily investing in combating climate change (Butt et al., 2018), and studies have shown that apart from increasing ecological value, investment in blue-green infrastructure and ecological restoration in cities has enormous socio-economic benefits for cities (Handel et al., 2013; Elmqvist et al., 2015). While ecosystem-based adaptation is gaining momentum, national and local decision makers are not yet able to fully incorporate these solutions due to a lack of monitoring systems and access to data and information on ecosystem health and relevant climate information (see AT19 discussion), along with the inability to implement innovative solutions that are relevant to the urban context (Bourne et al., 2016; Secretariat of the Convention on Biological Diversity, 2020).

Our analysis indicates that the most common subcategory within this theme is the restoration of aquatic or wetland ecosystems (52\% of plans), while the next most common is the restoration of degraded terrestrial habitats ( $40 \%$ of plans). Many plans (34\%) include steps to mitigate and adapt to climate change by boosting and integrating greening measures to sequester carbon and also cool the cities naturally. Coastal restoration projects have surged around megacities (Secretariat of the Convention on Biological Diversity, 2020). Some cities were observed to have mainstreamed ecological restoration by reorganizing urban design and planning practices that give special attention to indigenous/native species (Barcelona, Auckland, Washington, DC, Cardiff, and Nagoya) and to move away from conventional unsustainable planning and development practices that have thwarted natural processes in cities (Mostafavi and Doherty, 2016; Parris et al., 2018; Mata et al., 2020). For example, for the riverfront in Pimpri Chinchwad, biodesign techniques like bioremediation, phytoremediation, and others are being attempted. Some specific cities, such as Cardiff, Amsterdam, Berlin, and Leeds have planned to increase the coverage of reedlands or to restore wetlands to allow different species to nest and cross water barriers. These local scale restoration actions can serve as tangible contributions toward national-scale restoration targets and the global United Nations Decade on Ecosystem Restoration (2021-2030; see also the section "Comparing prevalence of Aichi Targets in biodiversity plans at the national and local scales"). Indeed, urban areas are identified as one of eight areas in which ecosystems can be restored (United Nations Environment Programme and Food and Agricultural Organization of the United Nations, 2021).

\section{Biodiversity Strategy and Action Plans Adopted (AT17)}

Aichi Target 17 refers to the creation of National Biodiversity Strategy and Action Plans. To interpret this theme at the local level, we looked for actions related to the establishment of biodiversity and biodiversity-related plans. The majority of plans $(77 \%)$ contained one or more actions addressing this theme. However, only $16 \%$ of biodiversity plans refer to creating, approving or updating a Local Biodiversity Strategy and Action Plan, though this may be simply because these cities have just adopted the plan itself. On the other hand, $45 \%$ of plans referred to creating a related plan, such as a conservation plan, habitat plan, species plan, green spaces plan, or management plan. This could imply that these cities see the current plan as the first step of conservation-related planning. Monitoring or reporting on biodiversity plans was also relatively common, with $41 \%$ of plans stating this intended action. Participatory planning was included in $34 \%$ of plans, and the implementation of the plan or a management plan was mentioned in $32 \%$ of plans. Participation has been shown to be correlated with increased integration of biodiversity across various aspects (social, economic, etc.) (Pierce, 2014) in addition to its ethical obligation. The establishment of plans at the global, national, regional and/or local scales can serve to translate policies into concrete actions at the relevant scales and allows for all of society to take responsibility for and to play a part on an urgent global issue. However, we do not know how policies at the varying governance levels, if any, may be aligned so as to reinforce actions that need to be taken for the conservation, protection and management of biodiversity.

\section{Knowledge Improved, Shared, and Applied (AT19)}

The proposal and adoption of Aichi Target 19 was motivated by the growing demand to provide readily accessible data that could be integrated and analyzed to support political decisions (Hardisty et al., 2013). Nonetheless, a top-down approach may face the challenge of ensuring consistency in subnational level implementation and measurement (Hudson et al., 2019). Thus, reporting progress on Aichi Target 19 by cities, as well as its insertion into national or international reporting systems, present a challenge. While standards for data collection and reporting are forming at global and sometimes national scales, they are not yet standardized at local scales (Pierce et al., 2020).

Aichi Target 19, "Knowledge Improved, Shared, and Applied" was the second most abundant theme in local plans, identified in $93 \%$ of the plans and averaging 7.7 actions per plan, which highlights the importance of this theme at the local level. Local actions mainly focused on information availability and promotion and sharing of knowledge. A large quantity of biodiversity data has been gathered in recent years (Bayraktarov et al., 2019); however, access to it remains difficult at several levels and scales, as data are often distributed in fragmented and heterogeneous datasets, and collected via different research methodologies and monitoring schemes (Hoffmann et al., 2014). Cities often do not have the basic data they need to plan for biodiversity, including baseline data about current status or maps of significant habitats or species of concern (Underwood et al., 2018). Actions for developing baseline or historical data on biodiversity were identified in $59 \%$ of the evaluated local plans followed by encouraging research on local conditions $(50 \%$ of plans), reinforcing the need for basic data availability at the local level. The next most common action subcategories were oriented toward ongoing monitoring or updates to existing data (39\%). Melbourne, for example, seeks through its strategy to establish a comprehensive baseline of species, vegetation communities, and habitats to inform decision making, guide management actions, and evaluate success, while the City of Dublin states an action to 
establish the current ecological status of sites to use as a baseline for measuring change.

Even in cases where cities have sufficient data, they often have issues incorporating it into local plans (Nilon et al., 2017). Other actions within this theme address this by seeking to increase the application of the data or to share the data, such as through public databases. An example of a typical type of action found across the cities is from Calgary: "Develop a database that integrates land use and biodiversity data to support strategic management of Calgary's ecosystems." Mexico City, for example, has an action to "Generate and update scientific knowledge about the three components of biological diversity: ecosystems, species, and genes," while Dublin City aims to "Work with the National Biodiversity Data Centre, Dublin Day Biosphere Partnership, and others, to publish annual up-to-date maps and inventories of taxonomic groups within Dublin City."

Actions to comply or coordinate with larger-scale government initiatives related to the collection and sharing of biodiversity information and implementation of plans were included in 25\% of local plans. Examples include complying with relevant national legislation (e.g., eThekwini), meeting national obligations to protect nationally threatened ecosystems at identified priority sites (e.g., Auckland Council), and participating with federal and national agencies (e.g., Paris and Oslo). Some (30\%) plans included reporting on the status of local biodiversity and information sharing. Oslo, for example, aims to "strengthen cooperation on biodiversity in municipal agencies, including by establishing procedures for the exchange and use of data on important areas for biodiversity."

On an even larger scale, $25 \%$ of the plans consider coordinating with existing international commitments, programs, or standards related to the collection and sharing of information. As an example, Lisbon aims to "be comparable with other municipalities at the international level (using the same intervention area delimitation standards and indicators)," while Marseille has as an action to "support national or international certification processes for recognizing biodiversity reservoirs." Nonetheless, there is no global consensus in the use of concepts, data, or infrastructure related to conservation planning (Hoffmann et al., 2014). These differences have impacts not only on the global scale but also at the city level. Thus, support for effective and flexible methods to gather data and standards for data reporting is needed for significant numbers of cities to participate in biodiversity strategies.

\section{Additional Themes Not Included in Aichi Targets \\ Coordination}

The most common theme found in local plans but not covered by the Aichi Target themes is coordination in the form of external coordination (34\%) with non-government actors such as private foundations, landowners, corporations, and nongovernmental organizations (NGOs), or vertical cooperation (20\%) across government scales. These actions are differentiated from AT19 which focuses on knowledge-sharing in that they do not explicitly indicate sharing knowledge. This finding highlights the importance that municipalities place in partnerships, collaborations, and alignment with other interventions for them to be able to fulfill their plans as discussed in prior research (Pierce et al., 2020). Interestingly, Paris and Nagoya listed actions to encourage and advocate to their respective governments at the provincial or national levels to take biodiversity into account in national planning and systems. While the theme of partnerships is not explicit as one of the 20 Aichi Targets, it is part of the overall Strategic Plan 2011-2020 (Secretariat of the Convention on Biological Diversity, 2021). On the other hand, the Singapore Index, which is designed to monitor biodiversity-related efforts at the local level, includes explicit indicators about partnerships (Singapore Index indicators 20 and 21; Chan et al., 2014).

\section{Policies and Regulations}

The second most common theme found in local plans but not covered by the Aichi Target themes is regulations and enforcements (32\% of plans), which are differentiated from Aichi Target 3 because these actions are not necessarily incentives. Actions in this theme include policy commitments on regulations and procedures for urban biodiversity. The planned actions ranged from investigating and reviewing local by-laws (Cape Town and Toronto) and strengthening institutions that apply environmental legislation (Mexico City) to more specific planned commitments such as developing a greenification tool to specify demands concerning the quality and quantity of urban nature in local planning (Copenhagen) and investigating policy and legal mechanisms for threatened species on road verges and other transport corridors (Christchurch). Hong Kong plans to enhance environmental impact processes to address ecological impacts. These policy commitments demonstrate a willingness on the part of the sampled cities to use local legislative tools to help protect and manage their local biodiversity.

\section{Operations}

A small minority of the plans detail procedural (2\%) or administrative (7\%) changes, procurement of resources (7\%), or staff increases (9\%) to improve the operations of the municipality. Based on measures outlined in these plans, cities are attempting to make efforts to plan for biodiversity by increasing capacity and efficiency of staff. Emphasis was given to capacity building, document management system and audits, as well as access to physical resources in the form of tools and materials for management systems. Uniquely, Cape Town had a detailed section to "ensure effective and efficient management of the biodiversity management" that the city viewed as crucial for their local biodiversity plan, including a "career-pathing and mentorship plan/programme."

\section{Human/Wildlife Conflicts and Trafficking}

While access to natural areas has been shown to have significant benefits for humans (see discussion of AT14 and throughout), the proximity between nature and people heightened in areas of human population density can result in conflict, either through interaction with pest species or through direct interaction with wildlife. For example, rare but serious attacks on humans from bears, mountain lions, and coyotes are of concern in the Los 
Angeles metropolitan area. Only 16\% of the plans mentioned these kinds of negative interactions. Barcelona typifies some of the language we observed related to pest management: "Implement a biodiversity-friendly pest, disease and weed management programme." In both Cape Town and Chicago, plans mentioned managing or creating new approaches to human-wildlife conflicts, while Washington DC, which had the most detailed actions, such as to generate a "reduction in density of whitetail deer," a species prone to overpopulation due to the loss of predators throughout the eastern United States. These actions are differentiated from the theme "Invasive Alien Species" (AT9) in that they do not indicate invasive species.

The trafficking of species is recognized as a specialized area of organized crime and a significant threat to wildlife (UNODC, 2020). Biodiversity-related crimes were addressed in $11 \%$ of plans through 11 broad actions that cover collection and trade of species, as well as actions to improve vigilance in detecting wildlife crime in general, mainly in São Paulo, Mexico City, and Hong Kong. Cooperation and integration of actions in all levels of jurisdiction, from global to local, through international frameworks such as the Convention on International Trade in
Endangered Species of Wild Fauna and Flora (known as CITES) will allow feedback for policy and enforcement changes.

\section{Comparing Prevalence of Aichi Targets in Biodiversity Plans at the National and Local Scales}

In order to compare our results on local biodiversity plans to activities at the national scale, we extracted data on national alignment with the Aichi Targets from the GBO-5 report (Secretariat of the Convention on Biological Diversity, 2020; see Figure 3). In this report, the $\mathrm{CBD}$ assessed the alignment of targets as stated in National Biodiversity Strategies with the Aichi Biodiversity Targets in terms of both scope and the level of ambition. Since parties to the CBD were encouraged to update their national biodiversity plans to incorporate the Aichi Targets, we would expect to see greater prevalence of the Aichi Target themes in national plans. Even though the nationally reported targets are not comparable to the locally reported actions, the side-by-side display of the national and local scale data does

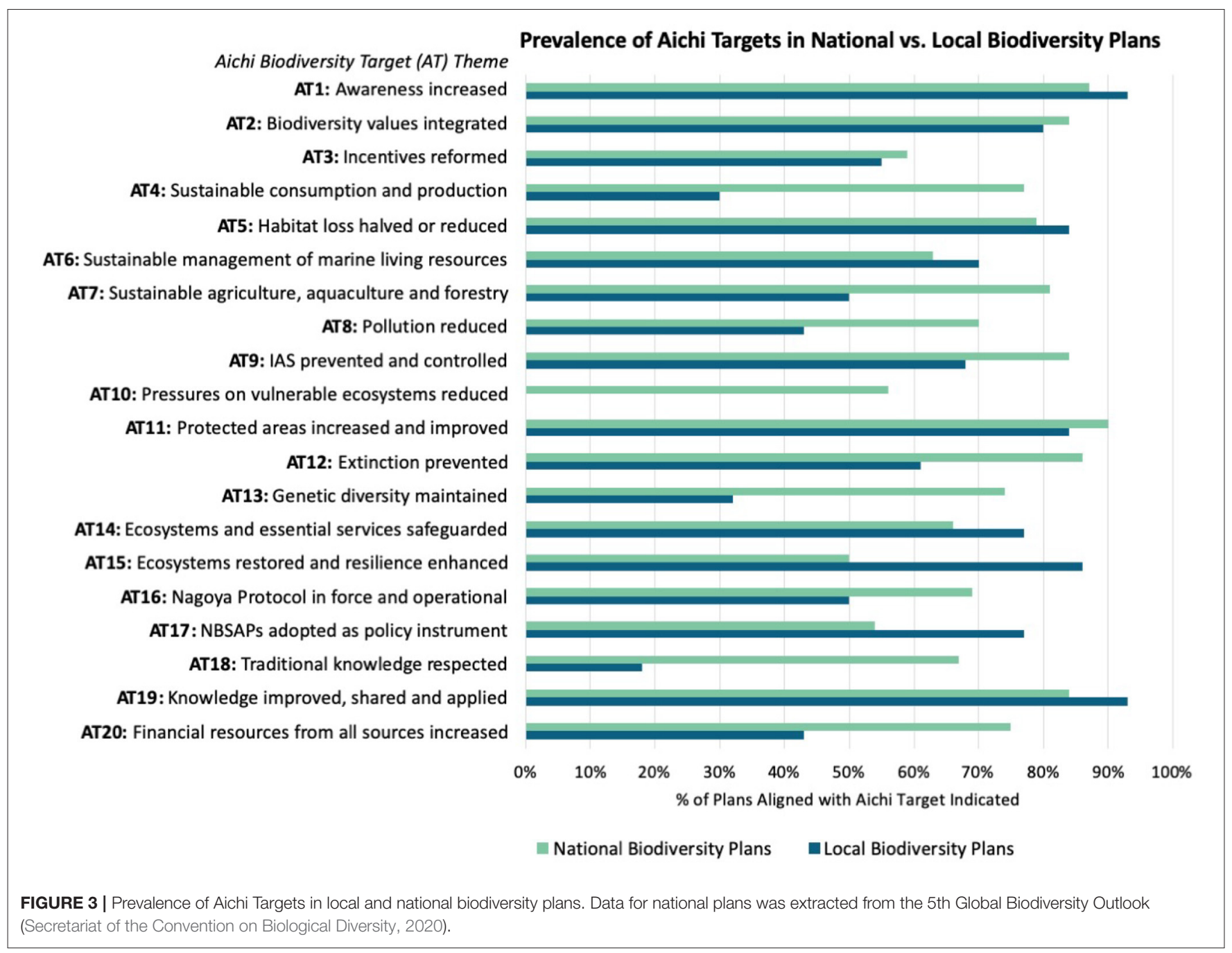


show the relative prevalence of different Aichi Target themes in biodiversity management at these two governance scales.

At the national and local scales, particular Aichi Target themes emerge as most prevalent, notably "Awareness increased" (AT1), "Biodiversity values integrated" (AT2), "Habitat loss halved or reduced" (AT5), "Protected areas increased and improved" (AT11), and "Knowledge improved, shared and applied" (AT19). This suggests that these themes hold significance across scales.

Six Aichi Target themes were more prevalent at the local than at the national scale. Of note, "Ecosystems restored and resilience enhanced" (AT15) was much more prevalent in local plans. We discussed the importance that municipal governments place on restoring ecosystems, which presents an opportunity for governments at other scales (i.e., national, regional) to coordinate with local governments on restoration efforts in urbanized spaces and to connect habitats across scales.

Some Aichi Target themes are less relevant or not applicable to particular urban contexts. For example, "Traditional knowledge respected" (AT18) may be part of federal jurisdiction. This is also the case for the "Nagoya Protocol in force and operational" (AT16), which also shows a higher prevalence at the national than at the local scale, reflecting the global scale of such agreements. In the case of "Sustainable consumption and production" (AT4), which is also more prevalent at the national scale, this may be partly due to greater data availability at the national level. Therefore, it is not surprising that these themes are more common in national rather than local plans.

Overall, our research supports Decision IX/28 by the CBD by finding that Aichi Target themes may be more comprehensively addressed through the integration of and collaboration between efforts at the national and subnational scales.

\section{Implications}

Our research may be useful for future agreements such as the Post-2020 Global Biodiversity Framework mentioned above, and the "Plan of Action on Subnational Governments, Cities, and Other Local Authorities for Biodiversity under the Convention on Biological Diversity (2021-2030)" which is currently being discussed and considered for adoption at the upcoming 15th Conference of the Parties (COP15). It may also be useful for local governments seeking to plan for biodiversity, or their collaborative partners. These findings may be used by these groups to identify areas of interest for

\section{REFERENCES}

Aronson, M. F. J., Piana, M. R., MacIvor, J. S., and Pregitzer, C. C. (2018). "Management of plant diversity in urban green spaces," in Urban Biodiversity: From Research to Practice, eds A. Ossola and J. Niemelä (London: Taylor and Francis), 101-120.

Barton, D. N., Grimsrud, K. M., Greaker, M., Heyman, A., Chen, X., Garnåsjordet, P. A., et al. (2017). "Monetary valuation methods in urban ecosystem accounting - examples of their relevance for municipal policy and planning in the Oslo metropolitan area," in Conference: London Group Meeting, "Methodology of SEEA CF and the Ecosystem Accounts," Costa Rica. Available online at: https://www.researchgate.net/publication/322096436_Monetary_ valuation_methods_in_urban_ecosystem_accounting_-_examples_of_their_ local governments, recognize the role of local governments in biodiversity conservation, and to provide supports where they are needed, such as in data collection, capacity building, increasing political supports for action, and in providing guidelines and standards specific to urban contexts.

Certain Aichi Target themes are commonly included in local biodiversity plans, and our findings suggest that it can be strategic to complement national efforts by coordinating them with local governments. However, to do so, more resources (monetary, human, or otherwise) are required, as is often mentioned in the local biodiversity plans we examined.

Future research that examines causal factors for differences between cities based on size, species diversity, indices of development, and other variables could further increase the ability to identify ways in which biodiversity conservation efforts could be improved.

\section{DATA AVAILABILITY STATEMENT}

The original contributions presented in the study are included in the article/supplementary materials, further inquiries can be directed to the corresponding author/s.

\section{AUTHOR CONTRIBUTIONS}

The authors contributed equally to this work, each being involved in the conceptualization, execution, analysis, discussion, and writing. JP was responsible for editing and the results. All authors contributed to the article and approved the submitted version.

\section{FUNDING}

This work was supported by National Science Foundation Grant \#1927468 and \#1927167, to the NATURA network of networks.

\section{ACKNOWLEDGMENTS}

We thank our current and former Urban Biodiversity Hub volunteers and student interns for contributing to the database from which we sampled city biodiversity plans. We also thank Yuki Takeda for assistance with the Japanese language translation and Melissa A. Barton for language editing.

relevance_for_municipal_policy_and_planning_in_the_Oslo_metropolitan_ area (accessed September 01, 2021).

Bayraktarov, E., Ehmke, G., O'Connor, J., Burns, E. L., Nguyen, H. A., McRae, L., et al. (2019). Do big unstructured biodiversity data mean more knowledge? Front. Ecol. Evol. 6:239. doi: 10.3389/fevo.2018. 00239

Berland, A., Shiflett, S. A., Schuster, W. D., Garmestani, A. S., Goddard, H. C., Herrmann, D. L., et al. (2017). The role of trees in urban stormwater management. Landsc. Urban Plan. 162, 167-177. doi: 10.1016/j.landurbplan.2017.02.017

Berting, J. (1980). What is the use of international comparative research?," in Problems in International Research in the Social Sciences, eds J. Berting, F. Geyer, and R. Jurkovich (Oxford: Pergamon Press), 159-177. 
Bourne, A., Holness, S., Holden, P., Scorgie, S., Donatti, C. I., and Midgley, G. (2016). A socio-ecological approach for identifying and contextualising spatial ecosystem-based adaptation priorities at the sub-national level. PLOS ONE 11:e0155235. doi: 10.1371/journal.pone.0155235

Butt, N., Shanahan, D. F., Shumway, N., Bekessy, S. A., Fuller, R. A., Watson, J. E. M., et al. (2018). Opportunities for biodiversity conservation as cities adapt to climate change. Geo Geogr. Environ. 5:e00052. doi: 10.1002/geo2.52

Chan, L., Hillel, O., Elmqvist, T., Werner, P., Holman, N., Mader, A., and Calcaterra, E. (2014). User's Manual on the Singapore Index on Cities' Biodiversity (also known as the City Biodiversity Index). Singapore: National Parks Board.

Chase, J. M., Blowes, S. A., Knight, T. M., Gerstner, K., and May, F. (2020). Ecosystem decay exacerbates biodiversity loss with habitat loss. Nature 584, 238-243. doi: 10.1038/s41586-020-2531-2

Cilliers, S., Cilliers, J., Lubbe, R., and Siebert, S. (2013). Ecosystem services of urban green spaces in African countries-perspectives and challenges. Urban Ecosyst. 16, 681-702. doi: 10.1007/s11252-012-0254-3

Cities Alliance (2007). Liveable Cities: The Benefits of Urban Environmental Planning. Washington, DC: Cities Alliance Secretariat.

Colautti, R. I., and MacIsaac, H. J. (2004). A neutral terminology to define 'invasive' species. Divers. Distribut. 10, 135-141. doi: 10.1111/j.1366-9516.2004.00061.x

Croci, E., Lucchitta, B., and Penati, T. (2021). Valuing ecosystem services at the urban level: a critical review. Sustainability 13:1129. doi: 10.3390/su13031129

Díaz, S., Demissew, S., Carabias, J., Joly, C., Lonsdale, M., and Ash, N. (2015). The IPBES conceptual framework-connecting nature and people. Curr. Opin. Environ. Sustain. 14, 1-16. doi: 10.1016/j.cosust.2014.11.002

Dickman, A., Johnson, P. J., Van Kesteren, F., and MacDonald, D. W. (2015). The moral basis for conservation: how is it affected by culture? Front. Ecol. Environ. 13:325-331. doi: 10.1890/140056

Doherty, T. S., and Ritchie, E. G. (2017). Stop jumping the gun: a call for evidence-based invasive predator management. Conserv. Lett. 10, 15-22. doi: $10.1111 /$ conl.12251

Elmqvist, T., Setälä, H., Handel, S. N., van der Ploeg, S., Aronson, J., Blignaut, J. N., et al. (2015). Benefits of restoring ecosystem services in urban areas. Curr. Opin. Environ. Sustain. 14, 101-108. doi: 10.1016/j.cosust.2015.05.001

Goddard, M. A., Dougill, A. J., and Benton, T. G. (2010). Scaling up from gardens: biodiversity conservation in urban environments. Trends Ecol. Evol. 25, 90-98

Gomez-Baggethun, E., Gren, A., Barton, D. N., Langemeyer, J., McPhearson, T., O'Farrell, P., et al. (2013). Urban Ecosystem Services. I: Urbanization, Biodiversity and Ecosystem Services: Challenges and Opportunities. A Global Assessment. Dordrecht: Springer.

Green, E. J., Buchanan, G. M., Butchart, S. H. M., Chandler, G. M., Burgess, N. D., Hill, S. L. L., et al. (2019). Relating characteristics of global biodiversity targets to reported progress. Conserv. Biol. 33, 1360-1369. doi: 10.1111/cobi. 13322

Hahs, A. K., McDonnell, M. J., McCarthy, M. A., Vesk, P. A., Corlett, R. T., Norton, B. A., et al. (2009). A global synthesis of plant extinction rates in urban areas. Ecol. Lett. 12, 1165-1173. doi: 10.1111/j.1461-0248.2009.01372

Handel, S. N., Osamu, S., and Kazuhiko, T. (2013). "Restoration ecology in an urbanizing world," in Urbanization, Biodiversity and Ecosystem Services: Challenges and Opportunities: A Global Assessment, eds T. Elmqvist, M. Fragkias, J. Goodness, B. Güneralp, P. J. Marcotullio, R. I. McDonald, S. Parnell, M. Schewenius, M. Sendstad, K. C. Seto, and C. Wilkinson (Dordrecht: Springer), 665-98. doi: 10.1007/978-94-007-7088-1_31

Hardisty, A., Roberts, D., and The Biodiversity Informatics Community (2013). A decadal view of biodiversity informatics: challenges and priorities. BMC Ecol. 13:16. doi: 10.1186/1472-6785-13-16

Harper, M. J., McCarthy, M. A., and van der Ree, R. (2005). The use of nest boxes in urban natural vegetation remnants by vertebrate fauna. Wildl. Res. 32, 509-516. doi: 10.1071/WR04106

Hoffmann, A., Penner, J., Vohland, K., Cramer, W., Doubleday, R., Henle, K., et al. (2014). The need for an integrated biodiversity policy support process - building the European contribution to a global Biodiversity Observation Network (EU BON). Nat. Conserv. 6, 49-65. doi: 10.3897/natureconservation.6.6498

Hudson, B., Hunter, D., and Peckham, S. (2019). Policy failure and the policyimplementation gap: can policy support programs help? Policy Design Pract. 2, 1-14. doi: 10.1080/25741292.2018.1540378
Ives, C. D., Lentini, P. E., Threlfall, C. G., Ikin, K., Shanahan, D. F., Garrard, G. E., et al. (2016). Cities are hotspots for threatened species: the importance of cities for threatened species. Glob. Ecol. Biogeogr. 25, 117-126. doi: 10.1111/geb.12404

Kabisch, N., Frantzeskaki, N., Pauleit, S., Naumann, S., Davis, M., Artmann, M., et al. (2016). Nature-based solutions to climate change mitigation and adaptation in urban areas: perspectives on indicators, knowledge gaps, barriers, and opportunities for action. Ecol. Soci. 21:39. doi: 10.5751/ES-08373210239

Kapos, V., Scharlemann, J., Campbell, A., Alison, A., Chenery, A., and Dickson, B. (2008). Impacts of Climate Change on Biodiversity: A Review of the Recent Scientific Literature. The United Nations Environment Programme World Conservation Monitoring Centre. Available online at: https://wedocs.unep.org/ bitstream/handle/20.500.11822/8629/Impacts-climate-change-biodiversity. pdf (accessed September 01, 2021).

Keeley, A. T. H., Basson, G., Cameron, D. R., Heller, N. E., Huber, P. R., Schloss, C. A., et al. (2018). Making habitat connectivity a reality. Conserv. Biol. 32, 1221-1232. doi: 10.1111/cobi.13158

Kendall, H. A., Lobao, L. M., and Sharp, J. S. (2006). Public concern with animalwell-being: place, social structural location, and individual experience. Rural Sociol. 71, 399-428. doi: 10.1526/003601106778070617

Kowarik, I. (2011). Novel urban ecosystems, biodiversity, and conservation. Environ. Pollut. 159, 1974-1983. doi: 10.1016/j.envpol.2011.02.022

Krippendorff, K. H. (2003). Content Analysis: An Introduction to Its Methodology. Thousand Oaks, CA: SAGE Publications, Inc.

Langemeyer, J., and Gómez-Baggethun, E. (2018). "Urban biodiversity and ecosystem services," in Urban Biodiversity - From Research to Practice, eds A. Ossola and J. Niemelä (New York, NY: Routledge), 36-53.

Lin, B. B., and Egerer, M. H. (2018). "Urban Agriculture: An opportunity for biodiversity and food provision in urban landscapes," in Urban Biodiversity: From Research to Practice, eds A. Ossola and J. Niemala (London: Taylor and Francis), 71-86.

Lin, B. B., Philpott, S. M., and Jha S. (2015). The future of urban agriculture and biodiversity ecosystem services: challenges and next steps. Basic Appl. Ecol. 16, 189-201.

Liu, Z., He, C., and $\mathrm{Wu}$, J. (2016). The relationship between habitat loss and fragmentation during urbanization: an empirical evaluation from 16 world cities. PLoS ONE 11:e0154613. doi: 10.1371/journal.pone.01 54613

Lyles, W., and Stevens, M. R. (2014). Plan quality evaluation 1994-2012: growth and contributions, limitations, and new directions. J. Plan. Educ. Res. 34 433-450. doi: 10.1177/0739456X14549752

Mair, L., Byers, O., Lees, C. M., Nguyen, D., Rodriguez, J. P., Smart, J., et al. (2021) Achieving international species conservation targets: closing the gap between top-down and bottom-up approaches. Conserv. Soc. 19, 25-33. Available online at: https://www.jstor.org/stable/26979975

Marselle, M. R., Stadler, J., Korn, H., Irvine, K., and Bonn, A. (eds.). (2019). Biodiversity and Health in the Face of Climate Change. Springer International Publishing. Available online at: http://library.oapen.org/handle/ 20.500.12657/22910

Mata, L., Ramalho, C. E., Kennedy, J., Parris, K. M., Valentine, L., Miller, M., et al. (2020). Bringing nature back into cities. People Nat. 2, 350-368. doi: $10.1002 /$ pan3.10088

Maxwell, S. L., Cazalis, V., Dudley, N., Hoffmann, M., Rodrigues, A. S. L., Stolton, S., et al. (2020). Area-based conservation in the twenty-first century. Nature 586, 217-227. doi: 10.1038/s41586-020-2773-z

McDonald, R. I., Colbert, M., Hamann, M., Simkin, R., Walsh, B., Ascensão, F., et al. (2018). Nature in the Urban Century: A Global Assessment of Important Areas for Safeguarding Biodiversity and Human Well-Being. Arlington, VA: The Nature Conservancy.

McNeely, J. (2001). Cities and Protected Areas: An Oxymoron or a Partnership? Parks 11, 1-3. Available online at: https:/www.iucn.org/sites/dev/files/import/ downloads/parks11_3.pdf (accessed September 01, 2021).

Merenlender, A. M., Crall, A. W., Drill, S., Prysby, M., and Ballard, H. (2016). Evaluating environmental education, citizen science, and stewardship through naturalist programs. Conserv. Biol. 30, 1255-1265. doi: 10.1111/cobi.12737

Millennium Ecosystem Assessment (Program) (2005). Ecosystems and Human Well-Being. Washington, DC: Island Press. 
Milner-Gulland, E. J., Addison, P., Arlidge, W. N. S., Baker, J., Booth, H., Brooks, T., et al. (2021). Four steps for the earth: mainstreaming the post-2020 global biodiversity framework. One Earth 4, 75-87. doi: 10.1016/j.oneear.2020. 12.011

Mostafavi, M., and Doherty, G. (eds.). (2016). Ecological Urbanism, Revised Edition (2016). Harvard University Graduate School of Design and Lars Müller Publishers.

Muller, N., Werner, P., and Kelcey, J. G. (eds.). (2010). Urban Biodiversity and Design (Conservation Science and Practice Series). Chichester: Wiley-Blackwell.

Mumaw, L., Maller, C., and Bekessy, S. (2017). Strengthening wellbeing in urban communities through wildlife gardening. Cities Environ. 10:6. Available online at: https://digitalcommons.lmu.edu/cate/vol10/iss1/6

Nilon, C. H., Aronson, M. F. J., Cilliers, S. S., Dobbs, C., Frazee, L. J., Goddard, M. A., et al. (2017). Planning for the future of urban biodiversity: a global review of city-scale initiatives. BioScience 67, 332-342. doi: 10.1093/biosci/bix012

Novoa, A., Shackleton, R., Canavan, S., Cybèle, C., Davies, S. J., DehnenSchmutz, K., et al. (2018). A framework for engaging stakeholders on the management of alien species. J. Environ. Manag. 205, 286-297. doi: 10.1016/j.jenvman.2017.09.059

Parris, K. M., Amati, M., Bekessy, S. A., Dagenais, D., Fryd, O., Hahs, A. K., et al. (2018). The seven lamps of planning for biodiversity in the city. Cities $83,44-53$. doi: 10.1016/j.cities.2018.06.007

Pierce, J. R. (2014). Planning for urban biodiversity in a divided world [Master's thesis]. Cornell University, Ithaca, NY, United States. doi: 10.13140/RG.2.2.35074.94400

Pierce, J. R., Barton, M. A., Tan, M. M. J., Oertel, G., Halder, M. D., Lopez-Guijosa, P. A., et al. (2020). Actions, indicators, and outputs in urban biodiversity plans: a multinational analysis of city practice. PLOS ONE 15:e0235773. doi: 10.1371/journal.pone.0235773

Puppim de Oliveira, J. A., Balaban, O., Doll, C. N. H., Moreno-Peñaranda, R., Gasparatos, A., Iossifova, D., et al. (2011). Cities and biodiversity: perspectives and governance challenges for implementing the Convention on Biological Diversity (CBD) at the city level. Biol. Conserv. 144, 1302-1313. doi: 10.1016/j.biocon.2010.12.007

Reed, D. H. (2012). "Impact of climate change on biodiversity," in Handbook of Climate Change Mitigation, eds W.-Y. Chen, J. Seiner, T. Suzuki, and M. Lackner (New York, NY: Springer US), 505-30.

Robbins, P., and Moore, S. A. (2013). Ecological anxiety disorder: diagnosing the politics of the Anthropocene. Cult. Geograph. 20, 3-19. doi: $10.1177 / 1474474012469887$

Rodrigues, A. S. L., Akçakaya, H. R., Andelman, S. J., Bakarr, M. I., Boitani, L., Brooks, T. M., et al. (2004). Global gap analysis: priority regions for expanding the global protected-area network. BioScience 54, 1092-1100. doi: 10.1641/ 0006-3568(2004)054[1092:GGAPRF]2.0.CO;2

Secretariat of the Convention on Biological Diversity (2008). "Decision IX/28: promoting engagement of cities and local authorities," in 9th Meeting of the Conference of the Parties to the Convention on Biodiversity. UNEP/CBD/COP/DEC/9/28. Available online at: https://www.cbd.int/doc/ decisions/cop-09/cop-09-dec-28-en.pdf (accessed September 01, 2021).

Secretariat of the Convention on Biological Diversity (2012). 14: Ecosystems and Essential Services Safeguarded. Quick Guide to the Aichi Biodiversity Targets.

Secretariat of the Convention on Biological Diversity (2013). Quick Guides to the Aichi Biodiversity Targets. Available online at: https://www.cbd.int/doc/ strategic-plan/targets/compilation-quick-guide-en.pdf (accessed July 1, 2020).

Secretariat of the Convention on Biological Diversity (2018). Actions to Enhance Implementation of the Strategic Plan for Biodiversity 2011-2020. Available online at: https://www.cbd.int/sp/actions.shtml (accessed September 16, 2021).

Secretariat of the Convention on Biological Diversity (2020). Global Biodiversity Outlook 5. Montreal, QC.

Secretariat of the Convention on Biological Diversity (2021). First Draft of the Post-2020 Global Biodiversity Framework. CBD/WG2020/3/3. Available online at: https://www.cbd.int/doc/c/abb5/591f/2e46096d3f0330b08ce87a45/wg202003-03-en.pdf (accessed September 01, 2021).

Sijtsma, F. J., van der Veen, E., van Hinsberg, A., Pouwels, R., Bekker, R., van Dijk, R. E., et al. (2020). Ecological impact and cost-effectiveness of wildlife crossings in a highly fragmented landscape: a multi-method approach. Landsc. Ecol. 35, 1701-1720. doi: 10.1007/s10980-020-01047-z
Silvertown, J. (2009). A new dawn for citizen science. Trends Ecol. Evol. 24, 467-471. doi: 10.1016/j.tree.2009.03.017

Smit, J., Nasr, J., and Ratta, A. (1996). Urban Agriculture: Food Jobs and Sustainable Cities. New York, NY: United Nations Development Programme (UNDP).

Smith, R. (2007). The development of the SEEA 2003 and its implementation. Ecol. Econ. 61, 592-599. doi: 10.1016/j.ecolecon.2006. 09.005

Solecki, W., Leichenko, R., and O'Brien, K. (2011). Climate change adaptation strategies and disaster risk reduction in cities: connections, contentions, and synergies. Curr. Opin. Environ. Sustain. 3, 135-141. doi: 10.1016/j.cosust.2011.03.001

Stern, M. J., Ardoin, N. M., and Powell, R. B. (2017). Exploring the effectiveness of outreach strategies in conservation projects: the case of the audubon Toyota TogetherGreen Program. Soc. Natural Resour. 30, 95-111. doi: 10.1080/08941920.2016.1164266

Trigger, D., Mulcock, J., Gaynor, A., and Toussaint, Y. (2008). Ecological restoration, cultural preferences and the negotiation of 'nativeness' in Australia. Geoforum 39, 1273-1283. doi: 10.1016/j.geoforum.2007. 05.010

Trzyna, T. (2014). Urban Protected Areas: Profiles and Best Practice Guidelines. Best Practice Protected Area Guidelines 22. Gland: IUCN. Available online at: https://portals.iucn.org/library/sites/library/files/documents/PAG-022.pdf (accessed September 01, 2021).

Underwood, E., Taylor, K., and Tucker, G. (2018). The use of biodiversity data in spatial planning and impact assessment in Europe. Res. Ideas Outcomes 4:e28045. doi: 10.3897/rio.4.e 28045

United Nations Environment Programme and Food and Agricultural Organization of the United Nations (2021). United Nations Decade on Ecosystem Restoration 2021-2030: Urban Areas. Available online at: https://www.decadeonrestoration. org/types-ecosystem-restoration/urban-areas (accessed August 10, 2021).

UNODC (2020). World Wildlife Crime Report 2020: Trafficking in Protected Species. New York, NY: United Nations. Available online at: https://www. unodc.org/documents/data-and-analysis/wildlife/2020/World_Wildlife_ Report_2020_9July.pdf (accessed September 01, 2021).

Wei, J. W., Lee, B. P. Y., and Wen, L. B. (2016). Citizen science and the urban ecology of birds and butterflies - a systematic review. PLoS ONE 11:e0156425. doi: 10.1371/journal.pone.01 56425

Weller, R., Drozdz, Z., and Kjaersgaard, S. P. (2019). Hotspot cities: identifying peri-urban conflict zones. J. Landsc. Architect. 14, 8-19. doi: 10.1080/18626033.2019.1623542

Wilby, R. L., and Perry, G. L. W. (2006). Climate change, biodiversity and the urban environment: a critical review based on London, UK. Progr. Phys. Geogr. Earth Environ. 30, 73-98. doi: 10.1191/0309133306pp470ra

Author Disclaimer: The views represented here are those of the authors and do not represent those of institutions other than the Urban Biodiversity Hub.

Conflict of Interest: The authors declare that the research was conducted in the absence of any commercial or financial relationships that could be construed as a potential conflict of interest.

Publisher's Note: All claims expressed in this article are solely those of the authors and do not necessarily represent those of their affiliated organizations, or those of the publisher, the editors and the reviewers. Any product that may be evaluated in this article, or claim that may be made by its manufacturer, is not guaranteed or endorsed by the publisher.

Copyright (C) 2021 Pierce, Drill, Halder, Tan, Tiwari and López Guijosa. This is an open-access article distributed under the terms of the Creative Commons Attribution License (CC BY). The use, distribution or reproduction in other forums is permitted, provided the original author(s) and the copyright owner(s) are credited and that the original publication in this journal is cited, in accordance with accepted academic practice. No use, distribution or reproduction is permitted which does not comply with these terms. 